\section{Genetics and preventive medicine: Beyond family history}

\section{To the Editor:}

Family history has traditionally served as a raw predictor of disease risk in patients. Recently, more attention has been paid to defining the best approach to eliciting this history and how it might better guide disease prevention protocols. Frezzo et al. ${ }^{1}$ and Scheuner ${ }^{2}$ discuss the development of a self-administered family history questionnaire for patients that appears easy to use and informative. Scheuner ${ }^{2}$ notes the "need for improvement in [family history documentation]" by primary care physicians and that this questionnaire appears a viable substitute for the time-consuming three-generation pedigrees physicians might otherwise construct. She continues that the introduction of such clinical tools, if proven valid, could revolutionize preventive medicine and "lead to the development of a public health campaign... Know your family history: It could save your life.”2

Though a noble vision, the ability to save lives based on family history information will require more than just empowering patients with knowledge of heritable diseases and providing physicians with risk-based algorithms for management. As we continue to learn about genetic influences on common diseases and, ideally, identify disease-associated gene loci, achieving improved disease prevention in general will demand a fundamental paradigm shift in medical practice-from a "reactive, disease-oriented medical culture toward a proactive, health-based one." 3

The public health community has already taken steps to achieve this. The Agency for Health Care Policy and Research spearheaded the "Putting Prevention into Practice Program" (PPIP) because there are "too many gaps between the prevention knowledge and tools that scientific advances have given us and the preventive care" patients receive. ${ }^{3}$ PPIP offers materials that enable clinicians to comply with recommended prevention guidelines and publishes handbooks encouraging patients to take an active role in disease prevention. These materials include an annual adult health risk profile for patients, containing direct questions about family history of hypertension, cardiovascular disease, hyperlipidemia, gastrointestinal and gynecological cancers, and glaucoma. ${ }^{4}$

Considering the efforts that have already gone into programs such as PPIP, approaches to achieving better genetic risk prediction and disease prevention, whether through self-administered family history questionnaires or direct genetic testing, might best be integrated into established prevention initiatives.

Claudia N. Mikail, MD, MPH

NIH Fellow in Medical Genetics Cedars-Sinai Medical Center Los Angeles, California

\section{References}

1. Frezzo TM, Rubinstein WS, Dunham D, Ormond KE. The genetic family history as a risk assessment tool in internal medicine. Genet Med 2003;5:84-91.

2. Scheuner MT. Family history: Where to go from here. Genet Med 2003;5:66-68.
3. Reynolds T. Putting prevention into practice: The physician's role. Ann Intern Med 1998;129:679-680. Available at www.acponline.org/journals/annals/pastiss/ 15oct98.htm. Accessed April 26, 2003.

4. Putting Prevention Into Practice. Adult Health Risk Profile (text version). Available at: http://www.ahcpr.gov/ppip/manual/profadul.htm. Accessed April 26, 2003.

\section{Response to Mikail}

To the Editor:

Thank you, Dr. Mikail, for your thoughtful response to the issues put forth in the recent article by Frezzo and colleagues ${ }^{1}$ and the accompanying editorial ${ }^{2}$ regarding use of family history to improve prevention efforts for common chronic diseases.

More than a noble vision, there are several reasons to believe that collection and interpretation of family history to identify and stratify risk and to guide screening and prevention recommendations could improve prevention efforts for most common chronic diseases and ultimately save lives. (1) There is under-utilization of many interventions known to be effective in improving health care $^{3}$ This may be due in part to the lack of effectiveness of a "one size fits all" approach to prevention. Personalized prevention messages with intensive management in high-risk individuals have the power to motivate behavior changes that can lead to improved prevention. ${ }^{4}$ (2) Family history is a powerful predictor of risk for many chronic diseases. It reflects not only genetic susceptibility but also the interactions between genetic, environmental, cultural, and behavioral risk factors. (3) Stratification of familial risk into different risk categories (e.g., average, moderate, and high) is possible by considering the number of affected family members, their degree of relationship to an index case, their ages of onset, the occurrence of associated conditions, and for some disorders, the gender of the affected family members. ${ }^{5}$ For many chronic disorders, this risk stratification should have greater clinical validity than assessing only the presence or absence of a family history, which is typical for most risk assessment instruments, such as the "Put Prevention into Practice" materials ${ }^{6}$ or the Adult Treatment Panel III guidelines for treatment of lipid disorders. ${ }^{7}$ (4) Familial risk stratification that recognizes high-risk cases and familial patterns of disease consistent with mendelian disorders can identify individuals who might benefit from genetic consultation and genetic testing to assess susceptibility to chronic diseases. Although the sequencing of the human genome holds great promise for clinical medicine and public health, it is unlikely that population-based applications of genetic testing for chronic diseases will develop in the near future due to our lack of understanding regarding prevalence and penetrance of disease susceptibility alleles, as well as gene-gene and gene-environment interactions. Rather, applications of genetic testing for chronic disease susceptibility will likely remain a clinical intervention based on personal and family history characteristics for many years to come. (5) Lastly, because risk factors for chronic diseases aggregate in families, ${ }^{8}$ a family-based approach to risk factor modification can be an effective strategy to promote healthy behaviors. ${ }^{9-11}$

Dr. Mikail states that steps have already been taken to improve disease prevention efforts with programs like "Putting Prevention into Practice," and that approaches to genetic risk prediction might best be integrated into established prevention initiatives. 
Certainly this would be one avenue for use of a family history tool. However, it is also reasonable to consider a family history tool that will stand on its own, particularly because one instrument has the ability to assess risk for multiple disorders. Regardless of how a family history collection and interpretation tool will be applied, research demonstrating the added value of the tool is necessary. ${ }^{12}$ It must have improved clinical validity (the ability to stratify and predict risk) compared to existing risk assessment methods. In addition, research proving feasibility and clinical utility is necessary before implementation into preventive medicine and public health practice. Without this proof, there will be little incentive for health care practitioners and consumers to change their behaviors and adhere to this approach. Ethical, legal, and social issues must also be researched to determine the acceptability of using a population-based family history tool. This research agenda will address the critical issues pertaining to integration of genetic information and technology into preventive medicine and public health practice. If successful, the results have the potential to revolutionize our approach to prevention and we will move closer to the paradigm shift Dr. Mikail speaks of, from reactive and diseaseoriented practice to proactive and health-based care.

Maren T. Scheuner, MD, MPH GenRISK Program, Cedars-Sinai Medical Center Associate Professor of Medicine, David Geffen School of Medicine at UCLA ATPM Fellow, CDC Office of Genomics and Disease Prevention

\section{References}

1. Frezzo TM, Rubinstein WS, Dunham D, Ormond KE. The genetic family history as a risk assessment tool in internal medicine. Genet Med 2003;5:84-91.

2. Scheuner MT. Family history: Where to go from here. Genet Med 2003;5:66-68.

3. CDC. Unrealized prevention opportunities: Reducing the health and economic burden of chronic disease. Atlanta, Georgia: U.S. Department of Health and Human Services, Centers for Disease Control and Prevention, 2000.

4. O'Malley PG, Feuerstein IM, Taylor AJ. Impact of electron beam tomography, with or without case management, on motivation, behavioral change, and cardiovascular risk profile. JAMA 2003;289:2215-2223.

5. Scheuner MT, Wang S-J, Raffel LJ, Larabell SK, Rotter JI. Family history: A comprehensive genetic risk assessment method for the chronic conditions of adulthood. Am J Med Genet 1997;71:315-324.

6. Expert Panel on Detection, Evaluation, and Treatment of High Blood Cholesterol in Adults. Executive summary of the third report of the national cholesterol education program (NCEP) expert panel on detection, evaluation, and treatment of high blood cholesterol in adults (adult treatment panel III). JAMA 2001;285:2486-2497.

7. Putting Prevention Into Practice. Adult Health Risk Profile (text version). Available at: http://www.ahcpr.gov/ppip/maunal/profadul.htm. Accessed May 13, 2003.

8. Brown DW, Giles WH, Burke W, Greenlund KJ, Croft JB. Familial aggregation of early-onset myocardial infarction. Commun Genet 2002;5:232-238.

9. Knutsen SF, Knutsen R. The Tromso Survey: The family intervention study-the effect of intervention on some coronary risk factors and dietary habits, a 6-year follow-up. Prev Med 1991;20:197-212.

10. Wood DA, Kinmonth AL, Davies GA, et al. Randomised controlled trial evaluating cardiovascular screening and intervention in general practice: Principal results of British family heart study. BMJ 1994;308:313-320.

11. Pyke SDM, Wood DA, Kinmonth AL, Thompson SG. Change in coronary risk and coronary risk factor levels in couples following lifestyle intervention. Arch Fam Med 1997;6:354-360.

12. Yoon PW, Scheuner MT, Khoury MJ. Research priorities for evaluating family history in the prevention of common chronic diseases. Am J Prev Med 2003;24:128135. 